\title{
Chemical Structure and Physical Properties of Heat-cured Poly(methyl methacrylate) Resin Processed with Cycloaliphatic Comonomer: An In Vitro Study
}

\author{
Ranganathan Ajay ${ }^{1}$, Karthigeyan Suma ${ }^{2}$, Ramajayam Sasikala ${ }^{3}$, Sekaran Sajidabegum ${ }^{4}$, Veerakumar Vignesh ${ }^{5}$, \\ Dharanividhya Bhuvaneshkumar 6
}

\begin{abstract}
Aim: The purpose of this in vitro research is to chemically characterize polymethyl methacrylate (PMMA) processed with $10 \%$ and $20 \%$ (v/v) tricyclodecane dimethanol diacrylate (TCDDMDA) comonomer. It also aimed to assess the degree of conversion (DC) and glass transition temperature $\left(T_{\mathrm{g}}\right)$ of the formed copolymers.

Materials and methods: The experimental groups were processed with the TCDDMDA comonomer (10\% and $20 \% \mathrm{v} / \mathrm{v})$, whereas the control group was processed only with the methyl methacrylate monomer. The copolymerization was studied by nuclear magnetic resonance (NMR) spectroscopy. The surface characteristics and composition (wt\%) were studied by field-emission scanning electron microscopy (FESEM) and energy dispersive X-ray (EDX) spectroscopy (cuboidal specimen; $5 \mathrm{~mm} \times 5 \mathrm{~mm} \times 3 \mathrm{~mm}$ ), respectively. The DC and $T_{\mathrm{g}}$ of the formed copolymers (powdered form) were analyzed by Fourier transform infrared spectroscopy and differential scanning calorimetry, respectively. One-way analysis of variance with post hoc Bonferroni test was used to compare the mean values of DC\% and $T_{\mathrm{g}}$ among the groups.

Results: The newly formed copolymer [P(MMA-Co-TCDDMDA)] was chemically characterized by NMR and FESEM-EDX. The DC and $T_{g}$ of the experimental groups were higher than the control. Tricyclodecane dimethanol diacrylate at $20 \%(\mathrm{v} / \mathrm{v})$ concentration showed the highest DC and $T_{\mathrm{g}}$. Conclusion: The addition of TCDDMDA comonomer improved the DC and $T_{\mathrm{g}}$ of the formed copolymer.

Clinical significance: The P(MMA-co-TCDDMDA) copolymer is expected to improve the mechanical properties and biocompatibility of the denture base acrylic resin. This would result in improved denture quality and durability, thereby, imparting a better quality of life to the geriatric population.
\end{abstract}

Keywords: Comonomer, Copolymer, Degree of conversion, Glass transition temperature, Tricyclodecane dimethanol diacrylate.

The Journal of Contemporary Dental Practice (2020): 10.5005/jp-journals-10024-2769

\section{INTRODUCTION}

Knowledge about the composition of a polymer plays a pivotal role in understanding the chemistry and clinical application of the material. The polymer composition (physical, chemical, and structural information of the molecules) and its distribution can be deduced using the most common method called nuclear magnetic resonance (NMR) spectroscopy. This is achieved by observing and studying the peaks of the NMR spectra. ${ }^{1}$

Polymethyl methacrylate (PMMA) is a widely used denture base resin material for the past 70 years. Although there are several advantages, unpropitious reactions to PMMA have been documented in the literature. ${ }^{2,3}$ The cell viability is chiefly influenced by the unreacted residual monomers in the resin specimens. The residual monomer content is predominantly governed by the degree of conversion (DC) achieved in the polymerization reaction. ${ }^{4,5}$ In denture base (vinyl) polymers, the DC is calculated from the ratio of aliphatic $C=C$ double bonds remaining in a cured specimen to $C=C$ bonds in the uncured specimen. Fourier transform infrared (FTIR) spectroscopy is one of the most commonly and widely used methods to evaluate the DC. ${ }^{6}$ This monomer to polymer conversion affects the mechanical properties of the polymerized resin. ${ }^{7-9}$ Improper or incomplete conversions affected the glass transition temperature $\left(T_{\mathrm{g}}\right)$ of the polymers. Hence, these polymers may be considerably more unstable at oral temperatures than highly converted polymers. ${ }^{9}$

From a clinical point of view, high credits are ceded to $T_{\mathrm{g}}$ as temperature generally influences the physicomechanical properties
${ }^{1}$ Department of Prosthodontics and Crown and Bridge, Vivekanandha Dental College for Women, Tiruchengode, Tamil Nadu, India

${ }^{2}$ Department of Prosthodontics and Crown and Bridge, Rajah Muthiah Dental College and Hospital, Annamalai University, Chidambaram, Tamil Nadu, India

${ }^{3-6}$ Department of Prosthodontics and Crown and Bridge, Vinayaka Mission's Sankarachariyar Dental College and Hospital, Salem, Tamil Nadu, India

Corresponding Author: Ranganathan Ajay, Department of Prosthodontics and Crown and Bridge, Vivekanandha Dental College for Women, Tiruchengode, Tamil Nadu, India, Phone: +91 8754120490, e-mail: jrangclassiq@gmail.com

How to cite this article: Ajay R, Suma K, Sasikala R, et al. Chemical Structure and Physical Properties of Heat-cured Poly(methyl methacrylate) Resin Processed with Cycloaliphatic Comonomer: An In Vitro Study. J Contemp Dent Pract 2020;21(3):285-290.

Source of support: Nil

Conflict of interest: None

of polymers. Denture base polymers are amorphous in nature which at sufficiently low temperature possess rigidity with brittleness. With the increase in temperature, they typically behave as flexible solids, rubber, or even as a viscous liquid. ${ }^{10}$ This transition from rigid brittle to flexible material is indicated by $T_{\mathrm{g}}{ }^{11}$ Thermal properties inclusive of $T_{\mathrm{g}}$ of denture base polymers have been primarily investigated by differential scanning calorimetry (DSC). ${ }^{12-14}$ 
Numerous modifications were attempted to improvise the physicomechanical and biological properties of PMMA. In recent years, monomeric modifications are becoming popular. ${ }^{15}$ However, the added comonomer has to interact and copolymerize with the proprietary methyl methacrylate (MMA) monomer. This is because copolymerization determines the properties of the denture base resins. ${ }^{16}$ To ameliorate the mechanical properties of the denture base polymer with a comonomer, it mandates a high interaction between the proprietary and the comonomer. This can be asseverated using field-emission scanning electron microscopy (FESEM) with energy dispersive X-ray (EDX) spectroscopy. For attaining detailed, high-resolution images of denture base surfaces, scanning electron microscopy has been widely replaced by FESEM. A microanalytical system is used in EDX, which depends on the $\mathrm{X}$-ray excitation of specimens for peak characterization based on the atomic structure. ${ }^{17}$

Tricyclodecane dimethanol diacrylate (TCDDMDA) is a novel cycloaliphatic, difunctional, dual-reactive, and cross-linking monomer. It has a unique steric hindrance property, whereby it slows down the polymerization rate and increases the monomer to polymer conversion. Hence, this study aims to deduce the organic structure and composition of the PMMA processed with $10 \%$ and $20 \%(\mathrm{v} / \mathrm{v})$ TCDDMDA comonomer by NMR ( ${ }^{1} \mathrm{H}-\mathrm{NMR}$ and $\left.{ }^{13} \mathrm{C}-\mathrm{NMR}\right)$ spectroscopy and FESEM-EDX, respectively. It also aims to assess the $\mathrm{DC}$ and $T_{\mathrm{g}}$ of the formed copolymers.

\section{Materials and Methods}

Nuclear magnetic resonance and DSC were carried out at the Department of Chemistry and Centralized Instrumentation and Service Laboratory, respectively, Annamalai University, Tamil Nadu. Field-emission scanning electron microscopy was performed at the University Science Instrumentation Center, Alagappa University, Tamil Nadu. Degree of conversion was executed at Centre for Nanoscience and Technology, KSR Institutions, Tamil Nadu.

Heat-cured denture base acrylic resin (DPI ${ }^{\oplus}$ Heat Cure; Dental Products of India, Mumbai, India) and cycloaliphatic monomer, TCDDMDA (Sigma-Aldrich, Germany; CAS Number 42594-17-2), were used in this study. Experimental monomers were prepared by substituting $10 \%$ and $20 \%(\mathrm{v} / \mathrm{v}$ ) of TCDDMDA in MMA. Methyl methacrylate without TCDDMDA served as control. The monomers were then stored in three separate identical dark glass bottles and labeled with appropriate concentrations. The investigator was blinded from the concentrations by covering the labels with opaque stickers. The bottles were then randomly numbered from one to three (Bottles 1, 2, and 3) to avoid expectation bias.

\section{Specimen Preparation}

One representative cuboidal specimen of each group $(5 \mathrm{~mm} \times 5 \mathrm{~mm}$ $\times 3 \mathrm{~mm}$ ) was prepared for FESEM-EDX. For all other experiments, disk-shaped $(22 \mathrm{~mm} \times 2 \mathrm{~mm}$ ) specimens $(n=10$ for each DC and DSC experiment) were fabricated. To obtain mold space, plastic acrylic dies of appropriate dimensions were used. The polymer and the monomer were proportionated at a 3:1 ratio in a porcelain jar. The dough forming time was 8 minutes for the control group and 15 minutes for experimental groups. The mold spaces were then packed with the dough at a packing pressure of 3,500 psi in mechanical press (Sirio Dental Srl, Meldola FC, Italy) for 10 minutes and then heat-cured at $74^{\circ} \mathrm{C}$ for 2 hours followed by terminal boiling treatment at $100^{\circ} \mathrm{C}$ for 1 hour in an acrylizer (Unident Instruments India Pvt Ltd). For NMR, DC, and DSC analyses, the polymerized
Table 1: Groups for the experiments

\begin{tabular}{lllll}
\hline & \multicolumn{3}{c}{ Groups } \\
\cline { 2 - 4 } Experiment & Control & \multicolumn{2}{c}{ Experimental } \\
\hline NMR & ${ }^{1} \mathrm{H}-\mathrm{NMR}$ & H NMRO & H NMR10 & H NMR20 \\
& ${ }^{13}$ C-NMR & C NMRO & C NMR10 & C NMR20 \\
FESEM-EDX & P(MMA) & P(MMA-CO- & P(MMA-Co- \\
DC & & 10TCDDMDA) & 20TCDDMDA) \\
DSC & & & \\
\hline
\end{tabular}

NMR, nuclear magnetic resonance; FESEM, field-emission scanning electron microscopy; EDX, energy dispersive X-ray; MMA, methyl methacrylate; TCDDMDA, tricyclodecane dimethanol diacrylate; DC, degree of conversion; DSC, differential scanning calorimetry

disk specimens of all groups were ground to powder particles with a clean tungsten carbide bur. The obtained powder was then sieved to obtain uniform particle size. ${ }^{18}$ All the polymeric specimens (powder/solid) were prepared by a single investigator to avoid bias. The study groups and their abbreviations are tabulated in Table 1.

A digital NMR spectrometer (Ultrashield ${ }^{\text {TM }} 400$ Plus; Bruker BioSpin, Karlsruhe, Germany) was used for the ${ }^{1} \mathrm{H}$ - and ${ }^{13} \mathrm{C}-\mathrm{NMR}$ spectra of the groups. A $20 \mathrm{mg}$ and $30 \mathrm{mg}$ powdered resin specimen was taken in a thin glass tube for ${ }^{1} \mathrm{H}$ - and ${ }^{13} \mathrm{C}-\mathrm{NMR}$, respectively. One milliliter of deuterated chloroform $\left(\mathrm{CDCl}_{3}\right)$ was added to the tube and shaken well to completely dissolve the powdered resin. Tetramethylsilane was preferred as an internal standard.

Field-emission scanning electron microscopy ( $\mathrm{FEI}^{\mathrm{TM}}$ Quanta $^{\mathrm{TM}}$ FEG 250, Oregon, USA) was used for characterizing the surface morphology of the groups. This machine was able to take images with high resolution. The cuboidal unfinished specimens were placed on the specimen mounts with appropriate labeling. Beam to specimen surface distance was $10 \mathrm{~mm}$. The specimen surfaces were scanned at $10 \mathrm{kV}$ with 3,000× magnification. The chemical composition of the specimens was measured with the aid of an EDX spectroscopy (Bruker India Scientific Pvt Ltd, Mumbai, India). The X-ray incident photons bombard the electrons of atoms, and the distribution of bombarded particles was detected through EDX. The graphical representation of the same was processed by in-built microanalysis software (Bruker Quantax Esprit).

The DC of monomer to polymer was determined by FTIR (Spectrum 100, Perkin Elmer, Singapore) with $4 \mathrm{~cm}^{-1}$ resolution and 16 scans at absorbance (Abs) mode. All heat-cured specimens, as well as the uncured material ( $n=10$ for each group), were analyzed. To obtain the FTIR spectrum of cured specimens, $2 \mathrm{mg}$ of specimen powder was mixed with $100 \mathrm{mg}$ of dry potassium bromide $(\mathrm{KBr})$ powder. The mixture was pressed into a disk of $0.5 \mathrm{~mm}$ thickness using a special mold and hydraulic pellet press. This pellet was placed vertically in the specimen compartment, and an infrared beam was transmitted. To prepare the uncured material, the prepolymerized resin powder was heated at $70^{\circ} \mathrm{C}$ for 30 hours. $^{18}$ This led to degradation of benzoyl peroxide and eschewed polymerization reactions of the material after mixing with the monomer. After mixing, the resin paste was placed between two polyethylene films, pressed to form a very thin film, and the infrared beam was passed. The DC was determined from the ratio of the Abs intensities observed for aliphatic $\mathrm{C}=\mathrm{C}$ and the carbonyl bond $\mathrm{C}=\mathrm{O}$ at $1,638 \mathrm{~cm}^{-1}$ and $1,720 \mathrm{~cm}^{-1}$ wavenumbers, respectively. These wavenumbers are frequently used as the internal standard of polymerized material for both the cured and uncured materials. The $D C$ was calculated using the following equation: 


$$
\mathrm{DC} \%=\left[1-\frac{\left(\frac{\text { Abs 1640 }}{\text { Abs 1720 }}\right) \text { Cured }}{\left(\frac{\text { Abs 1640 }}{\text { Abs 1720 }}\right) \text { Uncured }}\right] \times 100
$$

For $T_{\mathrm{g}}$, the specimens were tested in the DSC instrument (Netzsch, STA 449 F3 Jupiter ${ }^{\circledast}$, Selb, Germany) under nitrogen. Twenty milligrams of the powdered specimen were placed in an aluminum holder and heated from $50^{\circ} \mathrm{C}$ to $200^{\circ} \mathrm{C}$. The heating rate was set to $20^{\circ} \mathrm{C}$ minutes ${ }^{-1}$. In order to erase the thermal history of the specimen, all calculations were done using the data acquired from the second cycle. The $T_{\mathrm{g}}$ was estimated with the in-built software (Proteus ${ }^{\circledR}$ ) by drawing tangents on the heat flow curve at temperatures above and below the glass transition. The tangents were selected carefully because they have a significant effect on the reproducibility of the evaluation. It can be determined as the point of intersection of the bisector of the angle formed between the tangents with the measurement curve.

Statistical analysis was performed using SPSS Version 20.0 software. Preliminary results of the Shapiro-Wilks test indicated that the data were normally distributed $(p>0.05)$. Descriptive statistics, including mean, standard deviation (SD), standard error, maximum, and minimum, were calculated. Concerning inferential statistics, the level of significance between the three groups for DC and $T_{\mathrm{g}}$ was tested with one-way analysis of variance (ANOVA). To compare the groups, the post hoc Bonferroni test $(\alpha=0.05$ ) was performed. $p<$ 0.05 was considered for statistical significance.

\section{Results}

\section{NMR Spectroscopy}

The peak signals of ${ }^{1} \mathrm{H}-\mathrm{NMR}$ of control and experimental groups are shown in Figure 1. The protons in $-\mathrm{OCH}_{3}(\delta 3.533-\delta 3.532),-\mathrm{CH}_{2}$ backbone $(\delta 1.980-\delta 1.744)$, and $-\mathrm{CH}_{3}$ (H NMR0: $\delta 1.372-\delta 0.769 ; \mathrm{H}$ NMR10, 20: $\delta 1.370-\delta 0.773)$ were seen in both control and experimental groups. Additional protons in $-\mathrm{OCH}_{2}(\delta 4.964)$, aliphatic ring $(\delta 4.062-\delta$ $4.044, \delta 3.937-\delta 3.897$, and $\delta 2.108)$, and $\mathrm{CH}(\delta 2.986-\delta 2.947)$ were observed exclusively in experimental groups. The peak signals of ${ }^{13} \mathrm{C}-\mathrm{NMR}$ of control and experimental groups are shown in Figure 2.
The carbon $(\mathrm{C})$ atoms in $>\mathrm{C}=\mathrm{O}(\delta$ 178.14- $\delta 177.00),-\mathrm{O}-\mathrm{CH}_{3}(\delta 51.84)$, quaternary carbon ( $\delta 44.88$ and $\delta 44.53$ ), saturated alkane $\mathrm{CH}$ (CNMR0: $\delta$ 25.01; C NMR10, 20: $\delta$ 29.69), and $-\mathrm{CH}_{3}(\delta 18.72$ and $\delta$ 16.46) were seen in both control and experimental groups. Additional $\mathrm{C}$-atoms in $-\mathrm{O}-\mathrm{CH}_{2}(\delta 64.89)$ and tricyclic C-atoms $(\delta 40.51-\delta 31.27)$ were observed exclusively in experimental groups. There were no significant spectral differences between the experimental groups. The presence of these additional protons and carbons in experimental groups affirms the copolymerization of TCDDMDA with MMA in PMMA.

\section{FESEM-EDX}

In FESEM, the $\mathrm{P}(\mathrm{MMA})$ group has a highly irregular rough surface (Fig. 3A) with a "continental" appearance. Experimental groups rather have a regular lamellar surface (Figs $3 \mathrm{~B}$ and $\mathrm{C}$ ) with a "sanddune" appearance. The lamellar pattern is more regular in $\mathrm{P}$ (MMACo-20TCDDMDA; Fig. 3C) than the other. On the basis of the EDX analysis, C (60.52 wt\%) and O (39.48 wt\%) were the elements in the $\mathrm{P}(\mathrm{MMA})$ group. The $\mathrm{C}$-atoms in the $\mathrm{P}(\mathrm{MMA}-\mathrm{Co}-10 \mathrm{TCDDMDA})$ and $\mathrm{P}(\mathrm{MMA}-\mathrm{CO}-20 \mathrm{TCDDMDA})$ groups were $61.97 \mathrm{wt} \%$ and 66.18 $w t \%$, respectively. This increase in the $C$-atoms in the experimental groups is due to the additional TCDDMDA monomer.

\section{Degree of Conversion}

In the infrared charts of all groups (Fig. 4), two Abs peaks appeared at $1,638 \mathrm{~cm}^{-1}$ and $1,720 \mathrm{~cm}^{-1}$ for uncured specimens. This implies the presence of unreacted carbon-carbon double bond $(C=C)$. The Abs peak at $1,638 \mathrm{~cm}^{-1}$ dramatically disappeared with the cured specimens of both experimental groups. This is inferred as a reduced residual monomer. However, for the cured specimen of the $\mathrm{P}(\mathrm{MMA})$ group, a weak Abs peak at $1,638 \mathrm{~cm}^{-1}$ did appear, which suggests the presence of residual monomer. Table 2 presents the mean (SD) of the control and experimental groups. One-way ANOVA showed the level of significant differences among the groups ( $p=$ 0.000). Bonferroni multiple comparison tests (Table 3 ) showed a statistically significant difference between the groups $(p=0.000)$. The DC of experimental groups was higher than that of the control group. The DC of P(MMA-CO-20TCDDMDA) was greater than that of P(MMA-Co-10TCDDMDA).

\section{Differential Scanning Calorimetry}

One-way ANOVA (Table 2) showed the level of significant differences among the tested groups $(p=0.000)$. When compared between
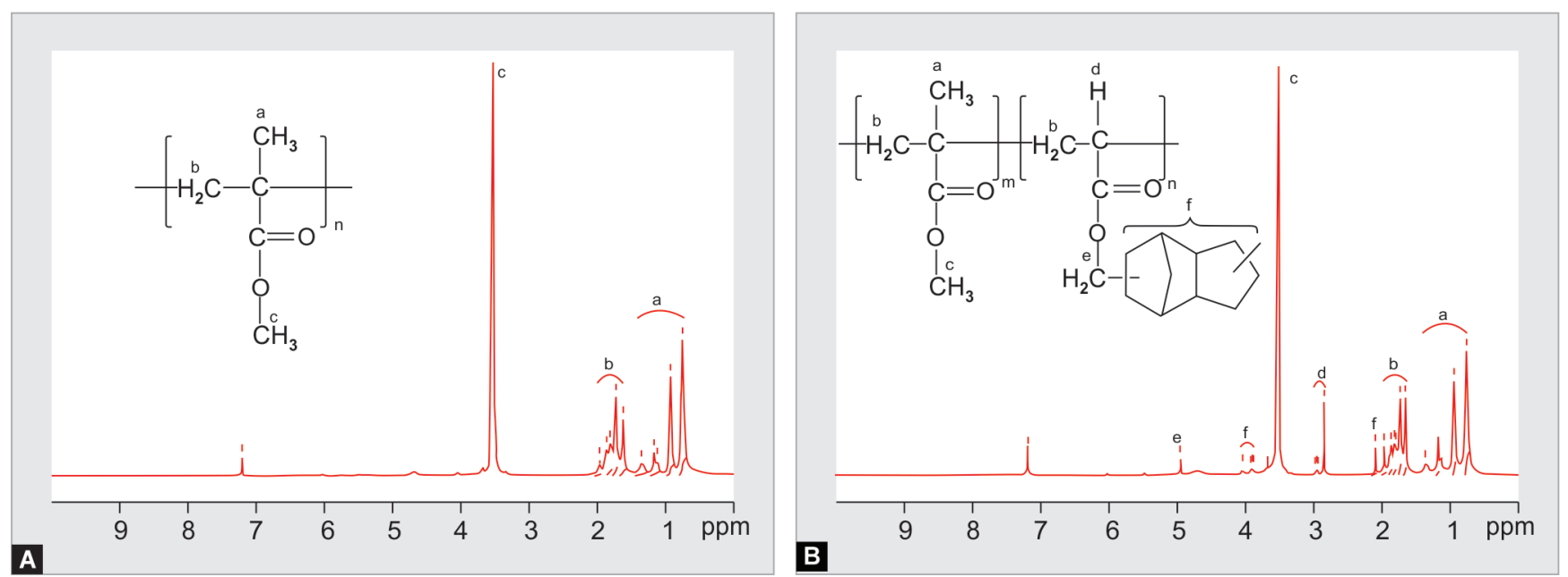

Figs $1 \mathrm{~A}$ and $\mathrm{B}:{ }^{1} \mathrm{H}-\mathrm{NMR}$ spectrum: (A) control group; (B) experimental groups 


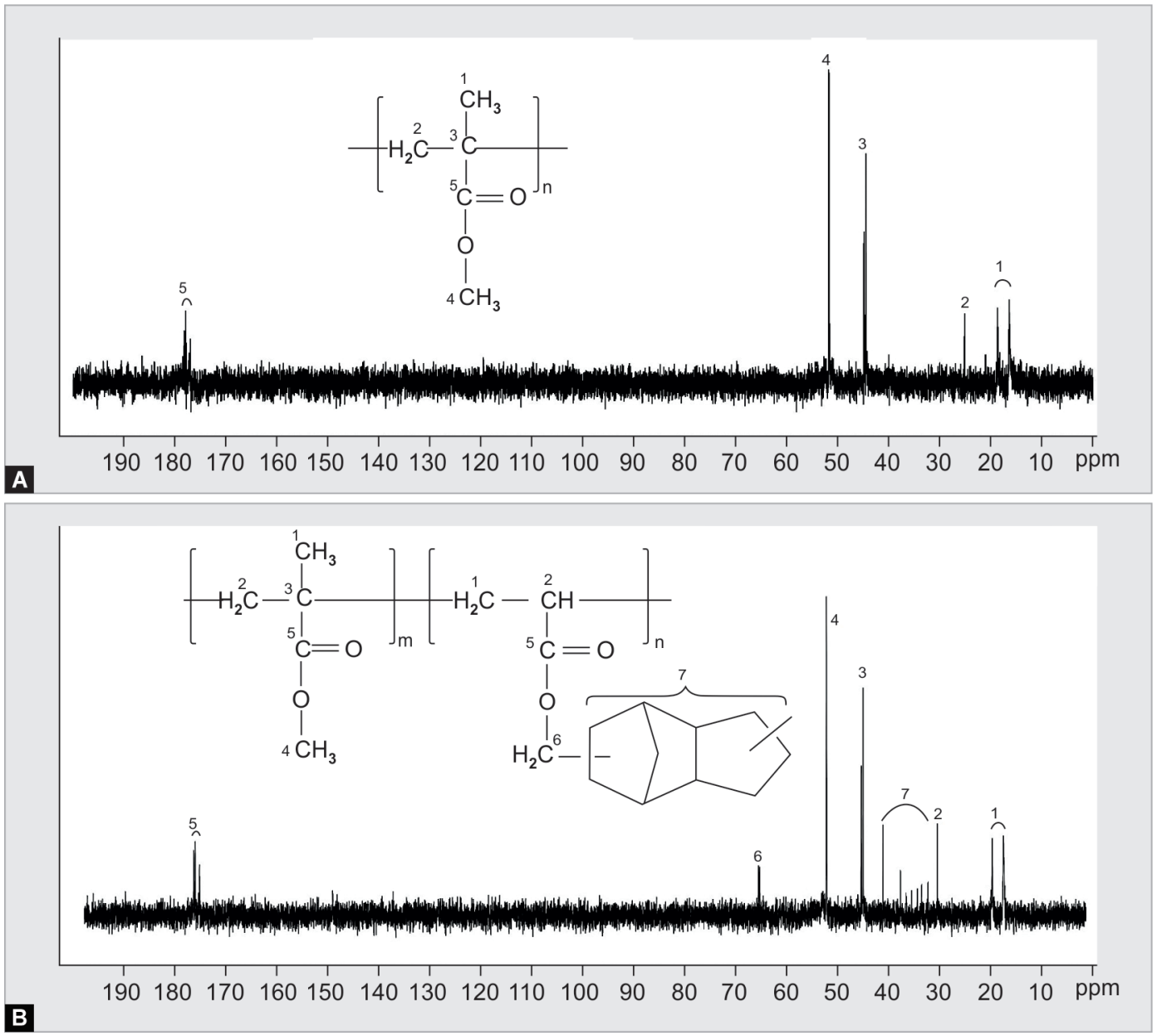

Figs $2 \mathrm{~A}$ and $\mathrm{B}:{ }^{13} \mathrm{C}-\mathrm{NMR}$ spectrum: (A) control group; (B) experimental groups
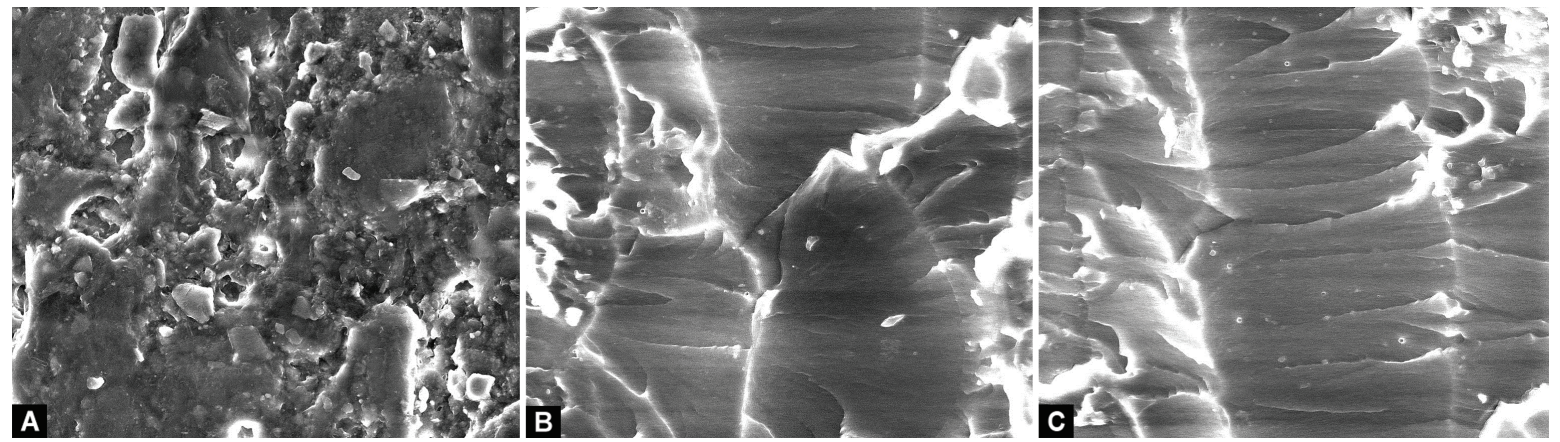

Figs $3 \mathrm{~A}$ to $\mathrm{C}$ : Field-emission scanning electron microscopy: (A) P(MMA); (B) P(MMA-co-10TCDDMDA); (C) P(MMA-co-20TCDDMDA)

the groups by Bonferroni multiple comparison tests (Table 3 ), there existed a statistically significant difference $(p=0.000)$. The $T_{\mathrm{g}}$ of experimental groups was higher than that of the control group. The $T_{g}$ of $\mathrm{P}(\mathrm{MMA}$-CO-20TCDDMDA) was slightly higher than that of P(MMA-CO-10TCDDMDA). Hence, the addition of TCDDMDA in MMA increased $T_{\mathrm{g}}$. Figure 5 shows the DSC curves of the groups with the $T_{\mathrm{g}}$ plot. Exothermic post/cold crystallization peak appeared at around $160^{\circ} \mathrm{C}\left(T_{\mathrm{c}}\right)$ in the experimental groups, which is absent in the $P(M M A)$ group.

\section{Discussion}

The present research demonstrated the influence of the copolymerization, which was caused by adding the TCDDMDA monomer, on the DC and $T_{\mathrm{g}}$ of heat-cured PMMA material. The structure of the PMMA was chemically modified by incorporating TCDDMDA ( $10 \%$ and $20 \% \mathrm{v} / \mathrm{v}$ ) to produce the P(MMA-Co-TCDDMDA) copolymer. Nuclear magnetic resonance spectroscopy of the experimental groups showed higher protons and C-atoms than the control group. This was further affirmed by EDX spectroscopy, which showed a higher $C$ weight percentage in experimental groups than the control. He et al. ${ }^{19}$ used antibacterial agents in methacrylate dental composites to evaluate the antibacterial activity, and they characterized the structure of the materials using NMR. Ayaz et al. ${ }^{20}$ copolymerized the acrylamide monomer with MMA. This was confirmed by the appearance of a new peak of the $-\mathrm{NH}_{2}$ functional group in the experimental groups. Therefore, ${ }^{1} \mathrm{H}$-and ${ }^{13} \mathrm{C}$-NMR spectroscopy along with EDX spectroscopy confirmed the formation of the P(MMA-Co-TCDDMDA) copolymer. 

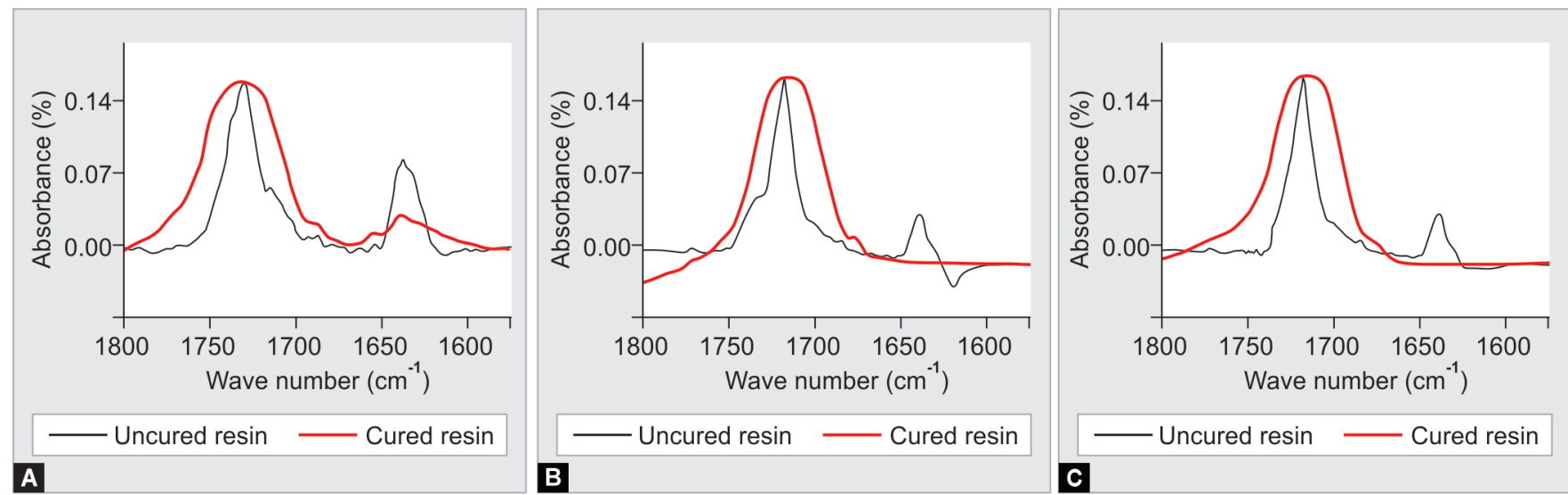

Figs 4A to C: Fourier transform infrared charts: (A) P(MMA); (B) P(MMA-co-10TCDDMDA); (C) P(MMA-co-20TCDDMDA)

Table 2: One-way ANOVA

\begin{tabular}{llll}
\hline Groups & Mean (SD) & Fvalue & pvalue \\
\hline I. DC (\%) & & & \\
P(MMA) & $78.56(0.84)$ & 305.577 & 0.000 \\
P(MMA-co-10TCDDMDA) & $83.77(0.79)$ & & \\
P(MMA-co-20TCDDMDA) & $87.05(0.67)$ & & \\
II. DSC $\left({ }^{\circ} \mathrm{C}\right)$ & & & \\
P(MMA) & $107.69(0.55)$ & 2644.431 & 0.000 \\
P(MMA-co-10TCDDMDA) & $123.35(0.55)$ & & \\
P(MMA-co-20TCDDMDA) & $125.33(0.67)$ & & \\
\hline
\end{tabular}

ANOVA, analysis of variance; SD, standard deviation; MMA, methyl methacrylate; TCDDMDA, tricyclodecane dimethanol diacrylate; DC, degree of conversion; DSC, differential scanning calorimetry

Table 3: Post hoc Bonferroni test

\begin{tabular}{|c|c|c|c|}
\hline Group & $\begin{array}{l}\text { Compared } \\
\text { group }\end{array}$ & $\begin{array}{l}\text { Mean } \\
\text { difference }\end{array}$ & Significance \\
\hline \multicolumn{4}{|l|}{ I. DC (\%) } \\
\hline \multirow[t]{2}{*}{$P(M M A)$} & $\begin{array}{l}\text { P(MMA-co- } \\
\text { 10TCDDMDA) }\end{array}$ & $-5.21^{*}$ & 0.000 \\
\hline & $\begin{array}{l}\text { P(MMA-co- } \\
\text { 20TCDDMDA })\end{array}$ & $-8.49^{*}$ & 0.000 \\
\hline $\begin{array}{l}\text { P(MMA-CO- } \\
\text { 10TCDDMDA) }\end{array}$ & $\begin{array}{l}\text { P(MMA-co- } \\
\text { 20TCDDMDA })\end{array}$ & $-3.28^{*}$ & 0.000 \\
\hline \multicolumn{4}{|l|}{ II. DSC $\left({ }^{\circ} \mathrm{C}\right)$} \\
\hline \multirow[t]{2}{*}{$\mathrm{P}(\mathrm{MMA})$} & $\begin{array}{l}\text { P(MMA-CO- } \\
\text { 10TCDDMDA) }\end{array}$ & $-15.66^{*}$ & 0.000 \\
\hline & $\begin{array}{l}\text { P(MMA-CO- } \\
\text { 20TCDDMDA })\end{array}$ & $-17.64^{*}$ & 0.000 \\
\hline $\begin{array}{l}\text { P(MMA-Co- } \\
\text { 10TCDDMDA) }\end{array}$ & $\begin{array}{l}\text { P(MMA-CO- } \\
\text { 20TCDDMDA) }\end{array}$ & $-1.98^{*}$ & 0.000 \\
\hline
\end{tabular}

*The mean difference is significant at the 0.05 level

MMA, methyl methacrylate; TCDDMDA, tricyclodecane dimethanol diacrylate; DC, degree of conversion; DSC, differential scanning calorimetry

The experimental groups had greater DC than the P(MMA) group. This increase in DC is attributed to reactive moieties. The acrylic moieties of diacrylates (TCDDMDA) are generally more reactive than methacrylic moieties of the MMA/ethylene glycol dimethacrylate cross-linker (EGDMA) and are thus used when faster reaction kinetics is desired. In the EGDMA cross-linker, after the first methacrylate group has reacted, the second pendant methacrylate

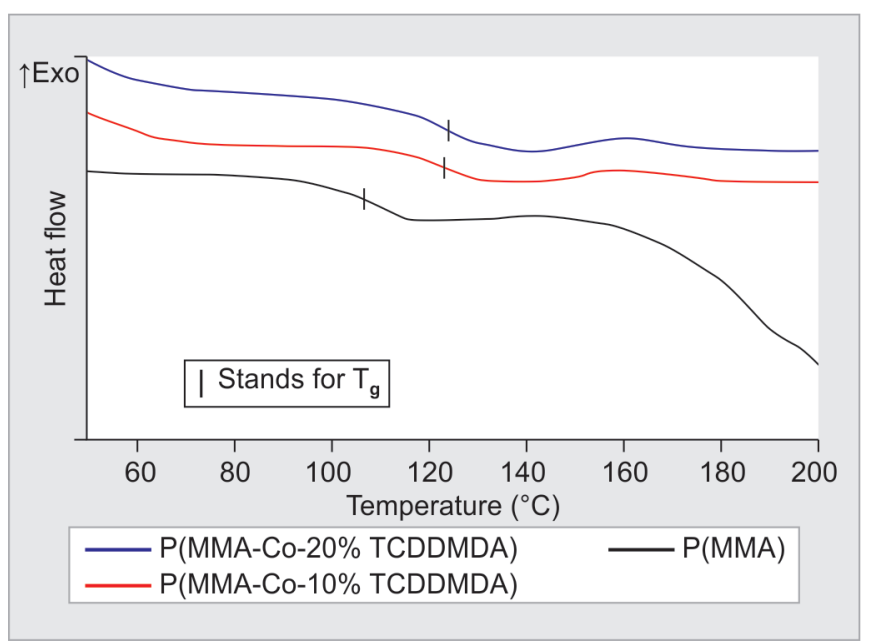

Fig. 5: Differential scanning calorimetry curves with $T_{\mathrm{g}}$ plot

group is estimated to be less reactive by 7.5-10 times. This leads to reduced final conversion for copolymerization of MMA with EGDMA. ${ }^{7}$ However, the faster reaction kinetics of acrylic moieties in TCDDMDA cause increased conversion thereby reducing the residual monomer content. In the FTIR spectra, the Abs peak at $1,638 \mathrm{~cm}^{-1}$ corresponds to the presence of unreacted residual monomer $(C=C)$. In this study, the disappearance of Abs peak at $1,638 \mathrm{~cm}^{-1}$ for the P(MMA-Co-TCDDMDA) copolymer suggests greater $\mathrm{DC}$ and lesser residual monomer than the $\mathrm{P}(\mathrm{MMA})$.

The addition of TCDDMDA to MMA increased the $T_{\mathrm{g}}$ of the P(MMA-Co-TCDDMDA) copolymer when compared to P(MMA). The exact relationship between the $T_{\mathrm{g}}$ and cross-linkers has not been established yet in the dental literature. From this study, it may be inferred that the cross-linker type determines the $T_{\mathrm{g}}$. However, Jerolimov et al. ${ }^{21}$ concluded that cross-linking PMMA by divinyl cross-linking agents can significantly alter $T_{\mathrm{g}}$. However, the relationship between $T_{\mathrm{g}}$ and cross-linker chain length and cross-linker concentration is complex. Also, different curing cycles produced $T_{\mathrm{g}}$ variations up to $20^{\circ} \mathrm{C} .{ }^{22}$ Apart from the TCDDMDA comonomer, certain other monomers have been experimented with MMA and studied its influence on $T_{\mathrm{g}}{ }^{15}$ For example, the addition of fluoro monomers in MMA increased the $T_{\mathrm{g}}{ }^{23,24} \mathrm{Kubota}$ et al. ${ }^{24}$ concluded that increase in the C-chain length increased the $T_{\mathrm{g}}$. However, itaconate ${ }^{25,26}$ and nitro-monomers ${ }^{14}$ decreased $T_{\mathrm{g}}$. Hence, from the aforementioned studies, it is apparent that the $T_{\mathrm{g}}$ is not only influenced by the $\mathrm{C}$-chain length but also by the type of comonomer added. 
In this study, concentrations of $10 \%$ and $20 \%$ (v/v) of TCDDMDA were substituted in MMA. The copolymerizing capability of TCDDMDA with MMA, DC, and $T_{\mathrm{g}}$ more than $20 \%$ have not experimented yet. This is the only research with the cycloaliphatic monomer in PMMA, and therefore, the results should be interpreted with caution. Further studies ought to be executed by increasing the concentration of TCDDMDA and its effect on the mechanical properties and biocompatibility.

\section{Conclusion}

Within the limitations of this research, the following conclusions can be deduced:

- There was evidence of copolymerization of the TCDDMDA comonomer with PMMA resin.

- Unfinished surface topography appeared lamellar along with high $\mathrm{C}$ wt\% in $\mathrm{P}$ (MMA-co-TCDDMDA) copolymers.

- The DC and $T_{g}$ were increased after the incorporation of TCDDMDA in the PMMA resin matrix. The P(MMA-Co20TCDDMDA) copolymer had the highest conversion and $T_{\mathrm{g}}$.

\section{Clinical Significance}

The study of copolymerization by adding a comonomer in denture resins provides a modification or reinforcement method, which is expected to improvise the mechanical properties and biocompatibility of the material. This will result in improved prosthetic (dentures) quality and durability, thereby, imparting a better quality of life to the geriatric population.

\section{References}

1. LiP, XuR, Wang W, et al. Thermosensitive poly(N-isopropylacrylamideco-glycidyl methacrylate) microgels for controlled drug release. Colloids Surf B Biointerfaces 2013;101(1):251-255. DOI: 10.1016/j. colsurfb.2012.07.009.

2. Brozek R, Koczorowski R, Rogalewicz R, et al. Effect of denture cleansers on chemical and mechanical behavior of selected soft lining materials. Dent Mater 2011;27(3):281-290. DOI: 10.1016/j. dental.2010.11.003.

3. Saitoh S, Sasaki K, Nezu T, et al. Viscoelastic behavior of commercially available tissue conditioners under compression. Dent Mater J 2010;29(4):461-468. DOI: 10.4012/dmj.2009-130.

4. Bural C, Aktas E, Deniz G, et al. Effect of leaching residual methyl methacrylate concentrations on in vitro cytotoxicity of heat polymerized denture base acrylic resin processed with different polymerization cycles. J Appl Oral Sci 2011;19(4):306-312. DOI: 10.1590/S1678-77572011005000002.

5. Borelli B, Zarone F, Rivieccio V, et al. Polyacrylic resins regulate transcriptional control of interleukin-6, gp80, and gp130 genes in human gingival fibroblasts. J Oral Sci 2017;59(1):87-91. DOI: 10.2334/ josnusd.16-0388.

6. Basso MF, Giampaolo ET, Vergani CE, et al. Influence of microwave disinfection on the dimensional stability of denture reline polymers. J Prosthodont 2010;19(5):364-368. DOI: 10.1111/j.1532849X.2010.00583.x.

7. Ruyter IE, Svedsen SA. Remaining methacrylate groups in composite restorative materials. Acta Odontol Scand 1978;40:359-376. DOI: 10.3109/00016358209024081.
8. Asmussen E. Restorative resins: hardness and strength vs. quantity of remaining double bonds. Scand J Dent Res 1982;90(6):484-489. DOI: 10.1111/j.1600-0722.1982.tb00766.x.

9. Ferracane JL, Greener EH. The effect of resin formulation on the degree of conversion and mechanical properties of dental restorative resins. J Biomed Mater Res 1986;20(1):121-131. DOI: 10.1002/ jbm.820200111.

10. McCabe JF, Walls AWG. Applied Dental Materials., 9th ed. Oxford: Blackwell Publishing Ltd; 2008. pp. 107-109, 124-125.

11. McCabe JF, Wilson HJ. Polymers in dentistry. J Oral Rehabil 1974;1(4):335-351. DOI: 10.1111/j.1365-2842.1974.tb01478.x.

12. Phoenix RD, Mansueto MA, Ackerman NA, et al. Evaluation of mechanical and thermal properties of commonly used denture base resins. J Prosthodont 2004;13(1):17-27. DOI: 10.1111/j.1532849X.2004.04002.x.

13. Urban VM, Machado AL, Alves MO, et al. Glass transition temperature of hard chairside reline materials after post-polymerisation treatments. Gerodontology 2010;27(3):230-235. DOI: 10.1111/j.17412358.2009.00312.x.

14. Rodriguez LS, Paleari AG, Giro G, et al. Chemical characterization and flexural strength of a denture base acrylic resin with monomer 2-tertbutylaminoethyl methacrylate. J Prosthodont 2013;22(4):292-297. DOI: 10.1111/j.1532-849X.2012.00942.x.

15. Ajay R, Suma K, Asharaf Ali S. Monomer modifications of denture base acrylic resin: a systematic review and meta-analysis. J Pharm Bioall Sci 2019;11(Suppl 2):S112-S125. DOI: 10.4103/JPBS.JPBS_34_19.

16. Ajay R, Suma K, JayaKrishnakumar $S$, et al. Chemical characterization of denture base resin with a novel cycloaliphatic monomer.J Contemp Dent Pract 2019;20(8):940-946. DOI: 10.5005/jp-journals-10024-2634.

17. Khanlou HM. FE-SEM and EDX characterization of sand blasted and sulfuric acid etched of novel biomaterial (Ti13Nb13Zr). Aust J Basic Appl Sci 2012;6(6):125-131.

18. Leão RS, de Moraes SLD, Aquino KAS, et al. Effect of pressure, postPressing time, and polymerization cycle on the degree of conversion of thermoactivated acrylic resin. Int J Dent 2018; 5743840. DOI: $10.1155 / 2018 / 5743840$.

19. He J, Soderling E, Osterbald M, et al. Synthesis of methacrylate monomers with antibacterial effects against S. Mutans. Molecules 2011;16(11):9755-9763. DOI: 10.3390/molecules16119755.

20. AyazEA, Durkan R. Influence of acrylamide monomer addition to the acrylic denture base resins on mechanical and physical properties. Int J Oral Sci 2013;5(4):229-235. DOI: 10.1038/ijos.2013.69.

21. Jerolimov V, Jagger RG, Millward PJ. Effect of cross-linking chain length on glass transition of a dough moulded poly(methylmethacrylate) resins. Acta Stomatol Croat 1994;28(1):3-9.

22. Jerolimov V, Jagger RG, Millward PJ. Effect of the curing cycle on acrylic denture base glass transition temperatures. J Dent 1991;19(4):245-248. DOI: 10.1016/0300-5712(91)90128-L.

23. Hayashi R, Kubota T, Mega J. Application of fluoroalkyl acrylate monomer for a denture base material. Int J Oral-Med Sci 2003;1(2): 124-129. DOI: 10.5466/ijoms.1.124.

24. Kubota T, Kobayashi M, Hayashi R, et al. Influence of carbon chain length of fluorinated alkyl acrylate on mechanical properties of denture base resin. Int J Oral-Med Sci 2005;4(2):92-96. DOI: 10.5466/ijoms.4.92.

25. Spasojevic P, Zrilic M, Panic V, et al. The Mechanical Properties of a Poly(methyl methacrylate) Denture Base Material Modified with Dimethyl Itaconate and Di-n-butyl Itaconate. Int J Polym Sci 2015; 1-9. DOI: $10.1155 / 2015 / 561012$.

26. Spasojevic P, Panic V, Seslija $S$, et al. Poly(methyl methacrylate) denture base materials modified with ditetrahydro furfuryl itaconate: significant applicative properties. J Serb Chem Soc 2015;80(9): 1177-1192. DOI: 10.2298/JSC150123034S. 